\title{
Why the pursuit of excellence matters
}

Previously published at www.cmaj.ca

$\mathrm{A}$ s our Olympic athletes prepare to compete in the 2010 Winter Games in Vancouver, we are reminded how important it is to strive to excel, not just in the final race but every day. The culture of excellence opens paths to success. It's a lesson we tend to forget.

In recent years, challenges in the health care system have left many of us feeling defeated, ${ }^{1}$ some even settling for mediocrity. We are facing new and formidable challenges: more aggressive diseases, sicker and more complex patients, mounting costs and increasing demand for health resources. Our leaders seem to be satisfied with providing timely access to essential services - a must, of course. ${ }^{2}$ But let's not be deluded into thinking that it is enough. Only those who strive for excellence will be able to lead us to solutions that will create the quality of health care all Canadians deserve.

Despite the challenges, many health care professionals exceed expectations every day. We go well beyond providing routine care for our patients; we help a student become a better, more compassionate physician; we work tirelessly to discover a cure for a disabling or lethal disease. However, as a collective, we often forget how important it is to constantly strive to be the best.

For institutions, this means meeting expectations of patients and, more often than not, working hard to exceed them. It means providing an environment in which some of the most skilled physicians and surgeons in the world are given the resources to care for patients, develop innovative treatments and teach - and inspire - the rest of us.

For clinicians, it means constantly improving the quality of care and ensuring that we are up to date with the latest evidence-based health interventions. It means that we need to be positive forces for change in the lives of patients by listening carefully, thinking critically and being compassionate. Although we may meet expectations most of the time, we should strive to exceed them. Every bit of extra effort is high yield for the immediate benefit of patients.

For those who teach medicine, it means ensuring that we not only provide our students and residents with the latest information and fairly represent treatment options but also go the extra mile. Be role models and mentors. Be attentive to the personal needs of the learners entrusted to us. It is not good enough to passively impart information. We should share our skills, knowledge and wisdom and pass on the thirst for excellence.
For Canada's research community, which in many disciplines is among the best in the world, excellence has to mean more than publishing articles and receiving grants. It means publishing key articles that change practice and receiving grants that foster innovation and new ideas. We should take on new agendas, work across many disciplines and programs and reach well beyond our comfort zone. ${ }^{3}$

Some would argue that there is a substantial opportunity cost to the pursuit of excellence. If we focus on investing all our resources on world-class programs, we might not have enough to provide equitable and accessible programs to all who need them. I agree. We must choose carefully where to invest our time, energy and money. But regardless of the choices, we must always strive for excellence.

Adopting the pursuit of excellence as an ideal in health care, health education and health research will ultimately generate innovations in care and better health outcomes. By promoting and celebrating excellence, Canada will enhance the contributions it already makes to solve the world's health problems, as well as our own.

Our Olympic athletes, many of whom have given up so much to vie for the podium, prove that the pursuit of excellence, and dreaming big, is not only possible, it is Canadian.

\section{Paul C. Hébert MD MHSc}

Editor-in-Chief, $C M A J$

With the editorial advisory team: Ken Flegel MDCM MSc, Noni MacDonald MD MHSc, Matthew B. Stanbrook MD PhD and Joan Ramsay BA

Competing interests: See www.cmaj.ca/misc/edboard.shtml

CMAJ 2010. DOI:10.1503/cmaj.092209

\section{REFERENCES}

1. Halbesleben JRB, Rathert C. Linking physician burnout and patient outcomes: exploring the dyadic relationship between physicians and patients. Health Care Manage Rev 2008;33:29-39.

2. 2003 First Ministers' accord on health care renewal. Ottawa (ON): Health Canada; 2006. Available: www.hc-sc.gc.ca/hcs-sss/delivery-prestation/fptcollab /2003accord/index-eng.php (accessed 2009 Dec. 18).

3. Health research roadmap. Creating innovative research for better health and health care. Ottawa (ON): Canadian Institutes of Health Research; 2009. Available: www.cihr-irsc.gc.ca/e/40490.html (accessed 2009 Dec. 18). 